Crowley N. \& Jevons M. P. (1955). J. gen. Microbiol. 13, 226-234

\title{
The Formation of a Starch-like Polysaccharide from Maltose by Strains of Streptococcus pyogenes
}

\author{
BY NUALA CROWLEY \\ Bacteriology Department, Royal Free Hospital School of Medicine, London \\ AND M. PATRICIA JEVONS \\ Bacteriology Department, Royal Free Hospital School of Medicine, London and \\ Central Public Health Laboratory, Colindale, London, N.W.
}

SUMMARY: Certain strains of Streptococcus pyogenes produced a starch-like substance in the presence of maltose and plasma. Amylolytic strains of group A streptococci produced larger amounts of the substance than other strains of these organisms. The substance was elaborated in the presence of optimal concentrations of plasma, with either starch, glycogen or maltose in the medium. It was not produced when either glucose-1-phosphate, glucose, cellobiose, melibiose, saccharose or lactose was substituted for maltose.

The amylolytic properties of certain strains of group A streptococci were reported by Keogh \& Simmonds (1940) and by Crowley $(1950,1954)$. The latter found that amylase production was a property of certain variants, and that amylase-positive organisms not infrequently lost the property during subculture on medium containing plasma. The effect of serum and plasma on amylase production was further studied, and this paper reports findings related to (1) the effect of plasma on the liberation of amylase, and (2) the formation of a starch-like substance.

\section{METHODS}

Strains. The history of six group A strains used is shown in Table 1. All of the strains were originally received from the Streptococcal Reference Laboratory, Public Health Laboratory Service.

Table 1. The group $A$ streptococci used in the experiments

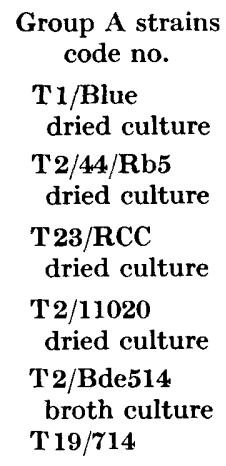

Isolation
By Griffith
(SF 130)
By Griffith
By Griffith
S.R.L. 1951
S.R.L. 1954
S.R.L. 1954

Animal
passages
Mouse 13
Mouse 44,
rabbit 4
None, fresh isolation
None, fresh isolation
None, fresh isolation


Culture media. Nutrient agar base (Crowley, 1954) was the minimal medium used. Pooled human plasma (citrated) was sterilized by filtration and added in the concentrations stated in the text. Substrates were prepared in concentrated solution and added as required. Soluble starch (AnalaR, British Drug Houses Ltd., London) and Amioca starch were autoclaved in sodium $\beta$-glycerophosphate $(2 \cdot 5 \%, \mathrm{w} / \mathrm{v}$, solution) at $\mathrm{pH} \mathbf{7 \cdot 8}$. Amylopectin powder was autoclaved in weighed quantities, the cold paste being made in sterile water and added to boiling glycerophosphate solution. Amylose was dissolved in $2 \mathrm{~N}-\mathrm{NaOH}$ with heat, neutralized with $5 \mathrm{~N}-\mathrm{HCl}$, and made up to volume as above. Glycogen and sugar solutions were sterilized by filtration. The highly purified corn amylose and corn amylopectin (intrinsic viscosity $\mathbf{1} \cdot \mathbf{0 7}$ ) were provided by the Northern Regional Research Laboratory of the U.S. Department of Agriculture, Peoria, Illinois. Glycogen (from mussels) was from a special batch prepared by Messrs Light and Co. Ltd, Colnbrook, Bucks., who also supplied $\beta$-maltose and D-glucose-1-phosphate (potassium salt).

Replica cultures were made from imprints on velveteen by the method of Lederberg \& Lederberg (1952). Master cultures were selected from tenfold culture dilutions made on blood agar plates, or from dilutions made and spread by the method of Asheshov \& Reagy (1951). Amylolytic colonies were detected by exposing plates to iodine vapour.

Gradient plates (Szybalski \& Bryson, 1952) were made with sloped layers of $20 \%$ plasma agar $(15 \mathrm{ml}$.$) and 2 \%$ starch agar $(15 \mathrm{ml}$.) as drawn in Fig. 1 . The plates were refrigerated for $48 \mathrm{hr}$. before use.

\section{RESULTS}

The effect of plasma on amylase production was tested with four of the group A strains shown in Table 1, which were grown on starch plasma gradient plates. Each of the four strains gave rise to different numbers of amylase-positive clones when blood agar cultures were replicated on starch agar. High plasma or serum concentrations may interfere with the formation of the starch-iodine complex, therefore uninoculated control plates were incubated with the cultures and exposed to iodine vapour at the same time. Four or six culture plates were incubated for each strain, one plate at a time being exposed to iodine vapour after different time intervals. Colonies were visible at the plasma side of the culture (see Fig. 1) after $4-8 \mathrm{hr}$. incubation, but amylase was not liberated by young cultures, being rarely detectable before $15 \mathrm{hr}$. at $37^{\circ}$.

\section{The effect of varied plasma/starch concentration on amylase production}

The colony variants of strain $\mathrm{T} 2 / 11020$ in gradient plate culture before and after exposure to iodine are shown in Fig. 1. Mucoid and matt variants growing in high plasma/low starch concentrations did not liberate amylase, whilst organisms growing in low plasma/high starch concentrations produced the enzyme. Colonies in the middle section of the plates were stained blueblack or blue by iodine in cultures of all four amylolytic strains. Mucoid 
colonies contained faint-staining rings. Matt and opaque colonies were either uniformly stained or ringed either centrally or at the periphery.

The experiments were repeated using gradient plates containing (1) soluble starch, (2) Amioca starch, and it was found that blue-staining colonies were
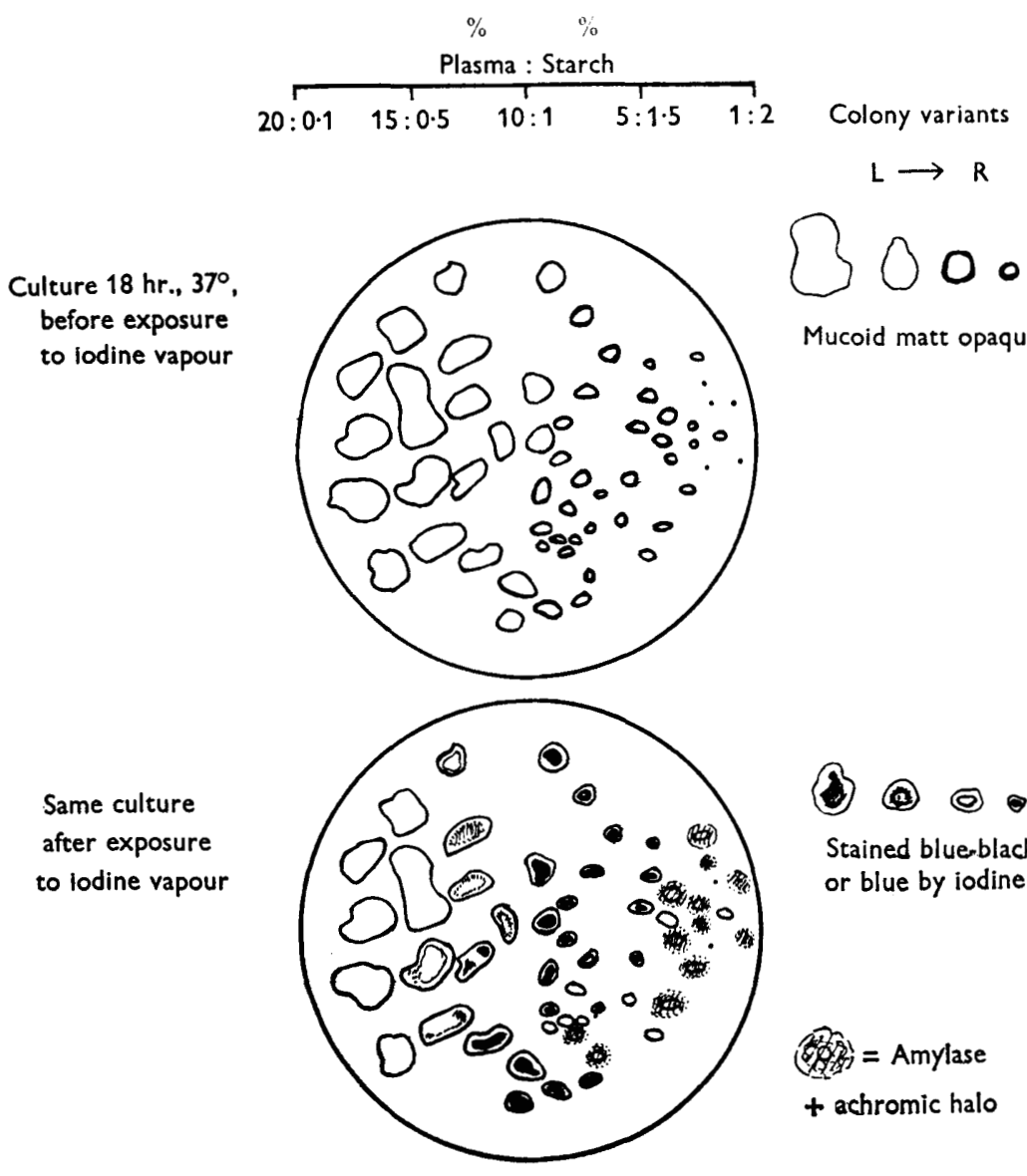

$$
L \rightarrow R
$$

Same culture after exposure to lodine vapour
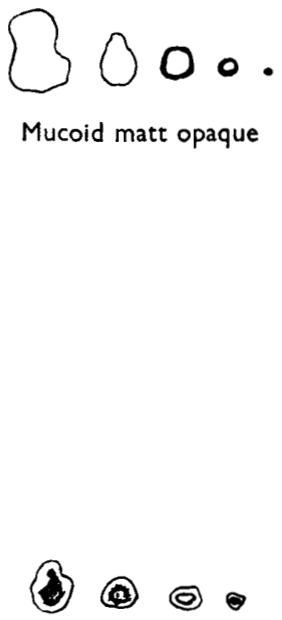

Stained bluerblack or blue by iodine

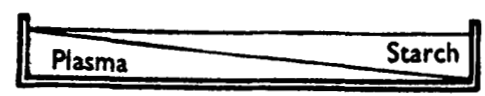

Fig. 1. Colony variants of a Type 2 strain on starch-plasma gradient plates.

present in cultures of all four amylolytic strains in plasma/substrate concentrations, range $4 / 0 \cdot 8 \%$ to $8 / 0 \cdot 4 \%$. Two amylase-negative strains $\mathrm{T} 23$ and T 19/714 also gave rise to a few blue-staining variants, but only in high substrate/low plasma concentrations. The experiment was then repeated using starch on plasma-layered plates containing (1) constant starch and varied plasma concentration, (2) constant plasma and varied starch concentration. Table $\mathbf{2}$ shows that amylase production was inhibited at plasma concentrations 


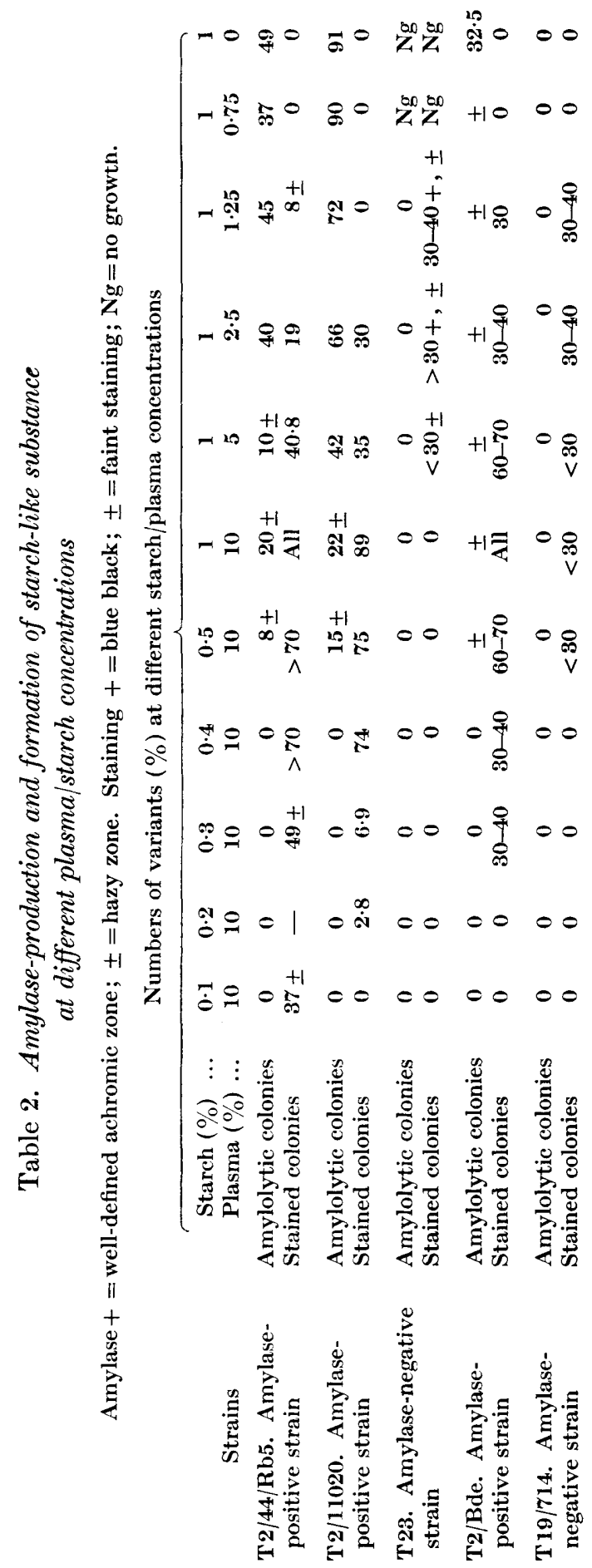


of $0.5 \%$ or higher, and that with amylase positive strains there was an inverse relationship between the numbers of amylolytic variants and blue-staining variants in the cultures.

\section{Microscopic appearance of streptococci in blue-staining colony variants}

Organisms were suspended in iodine solution (1 vol. $2 \%$ Lugol's iodine and 1 vol. $50 \%$ aqueous glycerol). Wet preparations were examined microscopically by phase-contrast illumination. The chains of cocci from mucoid colonies in overnight cultures were either (1) surrounded by large capsules, or (2) surrounded by small capsules, which varied in size, or (3) non-capsulated. Most of the organisms were unstained or slightly browned by iodine. A single coccus, or paired cocci in chains of 4 to 6 organisms would be stained bright azure blue by iodine. The blue cocci which were non-capsulated were usually larger than the rest, and giant forms were often at the end of a chain of cocci which had small capsules, so that the whole resembled a caterpillar.
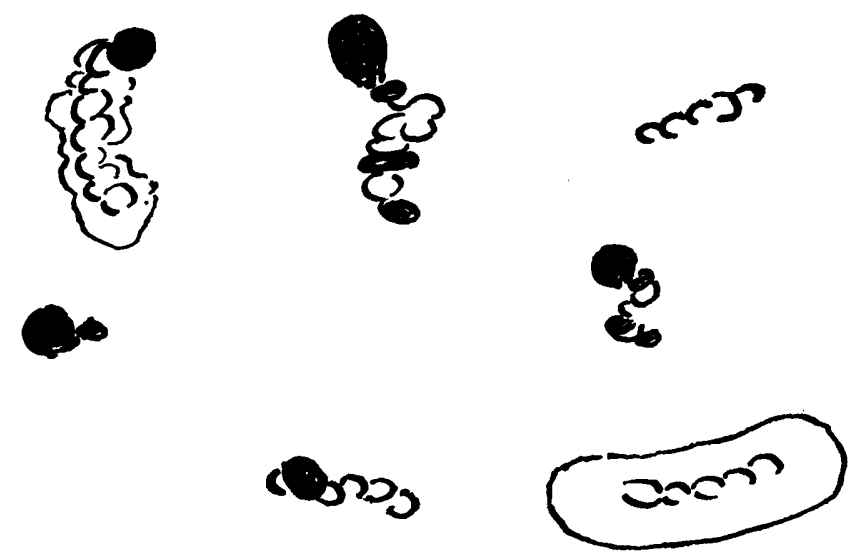

Fig. 2. Starchy streptococci from colony-variants on maltose agar. Shapes seen in iodineglycerol solution (phase contrast). Black shapes=azure blue cocci.

The formation of starch-like polysaccharide in the presence of other substrates

Three strains were tested for ability to produce the substance in the presence of amylose, amylopectin and glycogen. These preparations were all relatively pure compared with soluble starch or Amioca starch. It was probable, however, that all contained traces of maltose, which was included in the experiment together with glucose, glucose-1-phosphate, saccharose and lactose. The following procedure was adopted: The dried culture was reconstituted in broth, tenfold dilutions of which were inoculated on to blood agar. A suitable culture plate was selected and imprinted on velveteen, after which the masterculture was refrigerated. Replica cultures were made on blood-agar (2 plates) and on a set of polysaccharide or sugar media. One blood agar culture (1a) was replicated after 8-10 hr. at $37^{\circ}$ and the second blood agar culture (1 A), after $18 \mathrm{hr}$. incubation. The same culture pattern was therefore reproduced at 
two phases of growth, early and late. Repeated cultures on to different substrates were made from blood agar replicas of the original culture. After five subcultures, the population was compared with that of the master plate. The transfer error (Lederberg \& Lederberg, 1952; Elek \& Hilsdon, 1954) was within the range $10-15 \%$ and the range of the numbers of colonies on replica plates is shown in Table 3. In the presence of high plasma concentration, two of the strains formed confluent mucoid growth in which the starchy substance was detectable as a streak or ring near the edge of the growth, as in Fig. 1.

\section{Table 3. The formation of starch-like substance in the presence of different substrates}

$\mathrm{C}=$ confluence, mucoid colonies; $++=$ stained blue-black by iodine; $+=$ blue-green; $\pm=$ faint staining; $\mathbf{N g}=$ no growth.

* Numbers of colonies $(\%)$ containing starch-like substance

\begin{tabular}{|c|c|c|c|c|c|c|c|}
\hline Strains & $\begin{array}{l}\text { Human plasma (\%)... } \\
\text { Substrate }(\%) \ldots\end{array}$ & $\begin{array}{c}8 \\
0 \cdot 2\end{array}$ & $\begin{array}{c}8 \\
0 \cdot 4\end{array}$ & $\begin{array}{c}8 \\
0 \cdot 8\end{array}$ & $\begin{array}{c}4 \\
0 \cdot 8\end{array}$ & $\begin{array}{c}2 \\
0 \cdot 8\end{array}$ & $\begin{array}{c}0 \\
0 \cdot 8\end{array}$ \\
\hline T1/Blue & $\begin{array}{l}\text { Amylose } \\
\text { Amylopectin } \\
\text { Glycogen } \\
\text { Maltose } \\
\text { Glucose } \\
\text { Glucose-1-phosphate } \\
\text { Saccharose } \\
\text { Lactose }\end{array}$ & $\begin{array}{c}0 \\
0 \\
5 \pm \\
25 \pm \\
0 \\
0 \\
0 \\
0\end{array}$ & $\begin{array}{c}9 \pm \\
10 \pm \\
51 \pm \\
65 \pm \\
0 \\
0 \\
0 \\
0\end{array}$ & $\begin{array}{c}0 \\
0 \\
10 \pm \\
23+ \\
0 \\
0 \\
0 \\
0\end{array}$ & $\begin{array}{l}0 \\
0 \\
0 \\
4 \cdot 5 \pm \\
0 \\
0 \\
0 \\
0\end{array}$ & $\begin{array}{l}0 \\
0 \\
0 \\
0 \\
0 \\
0 \\
0 \\
0\end{array}$ & $\begin{array}{l}0 \\
0 \\
0 \\
\mathrm{Ng} \\
0 \\
0 \\
\mathrm{Ng} \\
\mathrm{Ng}\end{array}$ \\
\hline T $2 / 11020$ & $\begin{array}{l}\text { Amylose } \\
\text { Amylopectin } \\
\text { Glycogen } \\
\text { Maltose } \\
\text { Glucose } \\
\text { Glucose-1-phosphate } \\
\text { Saccharose } \\
\text { Lactose }\end{array}$ & $\begin{array}{l}\mathrm{C} / 0 \\
\mathrm{C} / 0 \\
\mathrm{C} / \pm \\
\mathrm{C} / \pm \\
\mathrm{C} / 0 \\
0 \\
\mathrm{C} / 0 \\
\mathrm{C} / 0\end{array}$ & 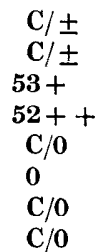 & $\begin{array}{l}6 \cdot 5 \pm \\
0 \\
23 \cdot 4+ \\
27++ \\
\text { C/0 } \\
0 \\
\text { C/0 } \\
\text { C/0 }\end{array}$ & $\begin{array}{l}0 \\
0 \\
4+ \\
6 \cdot 4+ \\
0 \\
0 \\
0 \\
0\end{array}$ & $\begin{array}{l}0 \\
0 \\
0 \\
0 \\
0 \\
0 \\
0 \\
0\end{array}$ & $\begin{array}{l}0 \\
0 \\
0 \\
0 \\
0 \\
0 \\
0 \\
0\end{array}$ \\
\hline T23 & $\begin{array}{l}\text { Amylose } \\
\text { Amylopectin } \\
\text { Glycogen } \\
\text { Maltose } \\
\text { Glucose-1-phosphate } \\
\text { Saccharose } \\
\text { Lactose }\end{array}$ & $\begin{array}{l}\mathrm{C} / 0 \\
\mathrm{C} / 0 \\
\mathrm{C} / 0 \\
\mathrm{C} / 0 \\
\mathrm{C} / 0 \\
\mathrm{C} / 0 \\
\mathrm{C} / 0\end{array}$ & $\begin{array}{l}\mathrm{C} / 0 \\
\mathrm{C} / 0 \\
\mathrm{C} / 0 \\
\mathrm{C} / 0 \\
\mathrm{C} / 0 \\
\mathrm{C} / 0 \\
\mathrm{C} / 0\end{array}$ & $\begin{array}{l}\mathrm{C} / \pm \\
\mathrm{C} / 0 \\
\mathrm{C} / \pm \\
\mathrm{C} / 0 \\
\mathrm{C} / 0 \\
\mathrm{C} / 0 \\
\mathrm{C} / 0\end{array}$ & 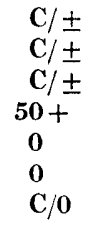 & $\begin{array}{l}\mathrm{C} / \pm \\
\mathrm{C} / \pm \\
64+ \\
93+ \\
0 \\
0 \\
0\end{array}$ & $\begin{array}{l}\mathrm{Ng} \\
\mathrm{Ng} \\
\mathrm{Ng} \\
\mathrm{Ng} \\
\mathrm{Ng} \\
\mathrm{Ng} \\
\mathrm{Ng}\end{array}$ \\
\hline
\end{tabular}

* The range of the numbers of colonies on the replica plates was as follows: $\mathrm{T} 1 /$ Blue, 92-128; T2/11020, 61-70; T23, 56-72.

Table 3 shows that the streptococci formed the blue-staining substance on maltose plasma agar, but it was not demonstrated in cultures containing saccharose, lactose, cellobiose, melibiose, glucose or glucose-1-phosphate. 'Blue variants' containing 'blue cocci' were demonstrated in the cultures containing glycogen, amylopectin or amylose, which are all composed of maltose chains.

When replica cultures of amylolytic strains were incubated for 2 days or longer, the 'blue substance' in marked colonies was stained with less intensity, 
and had frequently disappeared. This was attributed to amylase action. It seemed possible that, when the organisms had used up accessory growth factors necessary for the building up and conservation of the starch-like substance coating the cells, it became substrate for amylase. The blue iodine reaction is generally regarded as specific for starch complexes and amyloses. It seemed justifiable to conclude that the cells were coated with an amylose-like polysaccharide.

\section{The production of polysaccharide in the presence} of various growth-promoting factors

The results in Table 3 show that the starch-like polysaccharide was not produced by amylolytic strains from maltose in the absence of plasma. The amylase-negative T23 strain, which did not grow on maltose agar prepared with Hartley digest broth (Mackie \& McCartney, 1953), was cultured on nutrient agar prepared with broth infused according to the original method of Todd \& Hewitt (1932), without added peptone. Growth occurred on this medium when it was enriched with any of the substrates used in the previous experiments, though growth with amylose was very poor. Approximately $30 \%$ of the colonies contained the polysaccharide when either maltose, glycogen or starch components were added to the agar. This was about the same proportion as produced polysaccharide in the presence of plasma. On Todd-Hewitt agar the amylolytic strains produced amylase, and failed to produce the polysaccharide from maltose, glycogen or starch components. Synthesis of the polysaccharide occurred in the presence of bovine plasma, rabbit plasma, horse serum and human serum, but not with bovine albumin, human gamma globulin and human albumin.

\section{Inhibition by monoiodoacetic acid}

Replica cultures were made on maltose plasma agar containing different concentrations of monoiodoacetic acid. Before exposure to iodine, $18 \mathrm{hr}$. growth was replicated on control plates without inhibitor. The production of polysaccharide was completely inhibited by $0.00001 \mathrm{~m}$-iodoacetate. The control plates and control subcultures showed no inhibition. In a similar experiment the formation of polysaccharide was not inhibited by phlorizin $(0 \cdot 001-0.005 \mathrm{M})$.

\section{Formation of polysaccharide by representative group $A$ strains}

Fifty strains of group A streptococci of representative serological types were grown on ox-heart infusion agar containing Amioca starch (0.8\%). With the exception of glycogen, Amioca starch was the most sensitive substrate for detecting amylolytic activity. After $48 \mathrm{hr}$. incubation at $37^{\circ}$, weak amylase production was sometimes detectable underneath colonies or plaques of growth if the organisms were washed off the medium before exposing cultures to iodine. Fourteen strains were strongly amylase-positive after $48 \mathrm{hr}$. and twenty-six were amylase-negative. The same strains were then grown on agar 
containing (1) low substrate/high plasma concentration, (2) high substrate/ low plasma concentration. Cultures were exposed to iodine after $18 \mathrm{hr}$. at $37^{\circ}$. Table 4 shows that most strains which produced the polysaccharide were amylase-positive. Strongly positive strains required low substrate/high plasma medium for producing the polysaccharide but weakly positive strains required high substrate/low plasma medium. These observations suggest that, whilst maltose was the starter for the synthesis of the polysaccharide, the amount of the substance formed varied directly with the amylolytic properties of the strains.

\section{Table 4. Polysaccharide production by strains in a series of representative group $A$ serotypes}

Polysaccharide production,$+++++=$ well-stained colonies;,$+ \pm=$ faint staining. Serotypes which formed polysaccharide were members of types $1,2,4,12,13,14,19,22$, 25 and 6.

\begin{tabular}{|c|c|c|c|}
\hline \multirow[b]{2}{*}{ Group A strains } & \multirow[b]{2}{*}{$\begin{array}{l}\text { Numbers } \\
\text { of strains }\end{array}$} & \multicolumn{2}{|c|}{$\begin{array}{c}\text { Production of amylose-like } \\
\text { polysaccharide }\end{array}$} \\
\hline & & $\begin{array}{r}0.8 \% \text { maltose } \\
+2 \% \text { plasma }\end{array}$ & $\begin{array}{l}0.4 \% \text { maltose } \\
+8 \% \text { plasma }\end{array}$ \\
\hline Amylase-negative & 26 & $4+$ or \pm & o \\
\hline $\begin{array}{l}\text { Amylase-negative with } 10 \% \text { weakly } \\
\text { positive variants }\end{array}$ & 10 & $\begin{array}{c}9++ \\
+ \\
\pm\end{array}$ & $5+$ or \pm \\
\hline Amylase-positive & 14 & $\begin{array}{r}6+ \\
\pm\end{array}$ & $\begin{array}{c}14++ \\
++ \\
\pm\end{array}$ \\
\hline & 50 & 19 & 19 \\
\hline
\end{tabular}

Qualitative examination of culture plates suggested that strongly amylolytic strains form large amounts of polysaccharide, whereas other strains do not.

\section{DISCUSSION}

Bernfeld (1951), summarizing the various modes of biological synthesis of starch-like polysaccharides, distinguished four mechanisms. In two systems the starting substance is glucose-1-phosphate and the transferring enzymes are (1) phosphorylase and isophosphorylase, (2) phosphorylase and $\boldsymbol{Q}$ enzyme. Both mechanisms are inhibited by phlorizin. In a third system the starter is saccharose which is transformed into a glycogen-like polysaccharide by amylosucrase, an enzyme found in Neisseria perflava by Hehre \& Hamilton (1946). In the fourth, an amylomaltase found in the ML strain of Escherichia coli mutabile by Monod \& Torriani (1950) converts maltose into an amylose-like polysaccharide. The streptococcal mechanism clearly resembles the amylomaltase system. Though a fairly high proportion of strains of Streptococcus pyogenes are able to synthesize a starch-like polysaccharide when provided with maltose, certain strains can provide their own starting material by breaking down glycogen (or starch components) to produce a small amount of maltose in the culture. 
Culture filtrates of amylolytic streptococci rapidly degrade either amylopectin or glycogen, causing loss of viscosity during the first stage of the reaction, whilst only small amounts of maltose appear in the mixture (Crowley, 1955). Later on the reaction slows down, but maltose slowly increases in amount. In simplified medium with high substrate concentration, the amylase titre steadily rises in the culture, but it has been demonstrated that plasma (or a special factor) in the culture medium prevents the liberation of amylase except in small amounts. The same colony variants are capable of synthesizing an amylosaccharide from maltose, or of breaking down branched chain amylosaccharides. We do not yet know whether both mechanisms are possible in the same cell. We do know that in certain strains the amylase mutation rate is too high to measure by the method of Newcombe (1949) and that the same colony variants readily make large amounts of the starch-like substance from maltose. Crowley (1955) found that the strain T2/11020 also synthesized the amylosaccharide in broth enriched with plasma and maltose at $\mathrm{pH} \mathbf{7 \cdot 5}$. When extracted from the cells the amylosaccharide resembled amylose rather than glycogen.

\section{REFERENCES}

Asheshov, I. N. \& Reagy, F. C. (1951). A 'loop' method for counting viable bacteria or bacteriophage. Canad. J. med. Sci. 29, 1.

Bernfeld, P. (1951). Enzymes of starch degradation and synthesis. Advanc. Enzymol. 12, 379.

Crowley, N. (1950). The degradation of starch by strains of group A streptococei, having related antigens. J. gen. Microbiol. 4, 156.

Crowley, N. (1954). On amylolytic strains of Streptococcus pyogenes. J. gen. Microbiol. 10, 411.

Crowley, N. (1955). The action of streptococcal amylase in relation to the synthesis of an amylosaccharide by amylolytic strains of Streptococcus pyogenes. J. gen. Microbiol. 13, 218.

Elek, S. D. \& Hilsdon, G. R. F. (1954). Combined agar diffusion and replica plating techniques with study of antibacterial substances. J. clin. Path. 7, 37.

Hehre, E. J. \& Hamilton, D. M. (1946). Bacterial synthesis of an amylolytic-like polysaccharide from sucrose. J. biol. Chem. 166, 177.

Keogh, E. V. \& Sxmmonds, R. T. (1940). Cultural methods as an aid in type differentiation of group A haemolytic streptococci. J. Path. Bact. 50, 137.

Lederberg, J. \& Lederberg, E. M. (1952). Replica plating and indirect selection of bacterial mutants. J. Bact. 63, 399 .

Mackie, T. J. \& McCartney, J. E. (1953). Handbook of Practical Bacteriology. Edinburgh: E. \& S. Livingston.

Monod, J. \& Torriani, A. M. (1950). De l'amylo maltase d'Escherichia coli. Ann. Inst. Pasteur, 78, 65.

Newcombe, H. B. (1949). Origin of bacterial variants. Nature, Lond. 164, 12.

Szybalski, W. \& Bryson, V. (1952). Isolation of drug resistant mutants by gradient plate technique. J. Bact. 64, 489.

Todd, E. W. \& Hewitr, L. (1932). A new culture medium for the production of antigenic haemolysin. J. Path. Bact. 95, 873.

(Received 14 December 1954) 